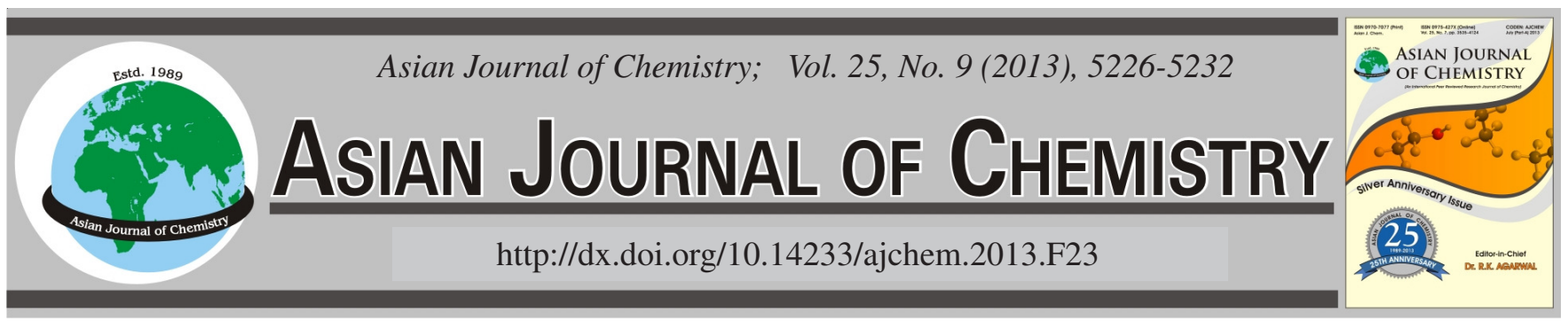

\title{
Comparison of Properties of Admicellar Polymerization Surface Modified Silica- and Conventional Fillers-Reinforced Tyre Tread Compounds $\dagger$
}

\author{
P. Toh-Ae ${ }^{1}$, T. Pongrrayoon ${ }^{2}$, N. Lopattananon ${ }^{1}$ and K. SAhakaro ${ }^{1, *}$
}

${ }^{1}$ Department of Rubber Technology and Polymer Science, Faculty of Science and Technology, Prince of Songkla University, Pattani 94000, Thailand

${ }^{2}$ Department of Chemical Engineering, Faculty of Engineering, King Mongkut's Institute of Technology, North Bangkok, Bangkok 10800, Thailand

*Corresponding author: Fax: +66 73 331099; Tel: +66 73 312213; E-mail: skannika@ bunga.pn.psu.ac.th

\begin{abstract}
Silanol groups on a silica surface lead to strong hydrogen bonding between the silica particles and aggregates, resulting in a poor dispersion of silica in rubber compounds. This study improved the compatibility between silica and rubber by coating the silica surface with a polyisoprene film using an admicellar polymerization technique. The modified silica was characterized by Fourier-transform infrared spectroscopy, thermogravimetric analysis and scanning electron microscopy. A comparison of the properties of natural rubber compounds filled with modified silica, silica with silane, carbon black and a mixed filler of silica and carbon black showed that the silicasilane filled compound exhibited the highest mixing torque and Mooney viscosity, whereas the modified silica-filled compound exhibited the lowest values. The silica-silane filled vulcanizates showed a higher modulus, reinforcing index, hardness and abrasion resistance than the vulcanizates containing modified silica. On the other hand, the modified silica-filled vulcanizates exhibited excellent ultimate tensile properties. The loss tangent at $0{ }^{\circ} \mathrm{C}$ and $60{ }^{\circ} \mathrm{C}$ of the vulcanizates filled with different types of fillers as well as filler dispersion are also discussed.
\end{abstract}

Key Words: Natural rubber, Silica, Modified silica, Tyre compounds, Reinforcement, Fillers.

\section{INTRODUCTION}

"Green Tyre Technology" has been introduced after the successful use of silica in combination with silane coupling agents in tyre tread compounds ${ }^{1}$ to reduce the rolling resistance and fuel consumption. Silica reduces the rolling resistance significantly and improves the wet traction of tyre tread compounds compared to carbon black ${ }^{2,3}$. The use of unmodified silica in non-polar rubber is associated with some processing difficulties derived from the difference in polarity between silica and rubber. The silanol groups on silica surface lead to strong hydrogen bonding between the silica particles and aggregates, causing a poor dispersion of silica in rubber compounds ${ }^{4}$. The dispersion stability and cure characteristics are also adversely affected by the polar nature of silica ${ }^{5}$. Amines or alcohols are commonly added to the compounds to prevent accelerator adsorption on the reactive silica surface and correct the cure properties ${ }^{6}$. On the other hand, strong filler-rubber interactions need to be promoted to optimize reinforcing efficiency of silica and silane coupling agents are normally employed for this purpose. The silane coupling agents commonly used in rubber compounds cured with a sulfur vulcanization system are bifunctional silanes that contain sulfur in the molecular structure, such as bis-(triethoxysilylpropyl) tetrasulfide (TESPT) and bis-(triethoxysilylpropyl) disulfide (TESPD $)^{7,8}$. The efficient mixing of silica in rubber compounds requires suitable mixing conditions because a chemical reaction between the silanol groups of silica and the alkoxy groups of silane, the so called silanization reaction, occurs during the mixing process. The dump temperature, i.e. the temperature of the compound at the end of the mixing step, was reported to be the key parameter governing the compound properties ${ }^{9-11}$.

In addition to the use of silane coupling agents, the compatibilization of silica and non-polar materials, such as natural rubber (NR) and styrene butadiene rubber (SBR), has been reported, e.g. through the use of polar rubber, such as chloroprene rubber $(\mathrm{CR})^{12}$, acrylonitrile butadiene rubber $(\mathrm{NBR})^{13,14}$, epoxidized natural rubber $(\mathrm{ENR})^{15}$ and maleated natural rubber $(\mathrm{MNR})^{16}$. In addition, the surface modification of silica using admicellar polymerization techniques has been

$†$ Presented to the International Rubber Conference (IRC-2012), May 21-24, 2012, Jeju, Republic of Korea 
investigated ${ }^{17-20}$. This technique involves the polymerization of an adsolubilized monomer within the adsorbed surfactant aggregated on the silica surface. The process consists of 4 steps: 1) admicelle formation using cationic surfactants, such as hexadecyltrimethylammonium bromide (CTAB); 2) monomer adsolubilization using a monomer type that is compatible with the polymer matrix; 3) polymer formation via radical polymerization and 4) removal of the outer surfactant layer on a polymeric film. Admicellar polymerization-surface-modified silica shows more hydrophobic and fewer agglomerates as well as better dispersion in natural rubber compounds ${ }^{20}$. Some studies on the properties of rubber compounds filled with the modified silica compared to unmodified silica showed that modified silica imparts superior properties, such as tensile strength, tear resistance and abrasion resistance ${ }^{18}$. On the other hand, the comparison was not performed under the optimum properties of unmodified silica, which needs to be used in combination with the silane coupling agent under proper mixing conditions. This study examined the properties of tyre tread compounds based on natural rubber filled with admicellar polymerization surface modified silica compared to those of the compounds reinforced with conventional fillers, e.g. carbon black and silica with a silane coupling agent. In addition to the use of single filler in the compounds, the properties of the compounds filled with a mixed filler of silica and carbon black were also studied comparatively. Each compound type with a different type of filler was prepared under optimal conditions to ensure that the comparison was made based on the maximum potential of each filler type.

\section{EXPERIMENTAL}

For the preparation of modified silica, Hi-Sil®255 (Tokuyama Siam Silica, Thailand), cetyltrimethylammonium bromide (CTAB) (98\%, Fluka Switzerland), potassium persulfate, $\mathrm{K}_{2} \mathrm{~S}_{2} \mathrm{O}_{8}$ (Fluka, Switzerland), ethanol (Fisher Scientific, USA) and isoprene monomer (Aldrich, USA) were used in the admicellar polymerization process. The following chemicals were used for compound preparation: Standard Thai Rubber 20 (STR20) (ThaiTech Rubber Corporation, Thailand), zinc oxide (Thai-Lysaght, Thailand), stearic acid (Imperial Chemical, Thailand), sulfur (Siam Chemicals, Thailand), paraffin wax, carbon black (N330) (Thai Carbon Black, Thailand), Hi-Sil®255 (Tokuyama Siam Silica, Thailand), Bis[3-(triethoxysilyl)propyl] tetrasulfide (TESPT) (Zhenjiang Wholemark Fine Chemicals, China), diethylene glycol (DEG) (TOC Glycol, Thailand), N-tert-butyl-2-benzothiazyl sulphenamide (TBBS), N,N'-diphenylguanidine (DPG), N(1,3-Dimethylbutyl)-N'-phenyl-p-phenylenediamine (6PPD), 2,2,4-trimethyl-1,2-dihydroquinoline (TMQ) (all from Flexys, Belgium) and treated distillate aromatic extract (TDAE) oil (H \& R ChemPharm, Thailand). All materials were used as received.

Preparation and characterization of modified silica: An aqueous solution of CTAB (145.8 g in $16 \mathrm{~L}$ ) was first prepared by stirring for $1 \mathrm{~h}$. Silica $(800 \mathrm{~g})$ was then added and stirred continuously for $2 \mathrm{~h}$ at room temperature to allow admicelle formation. The mixture was transferred from the mixing tank to the reactor tank. Ethanol (1,000 mL), $\mathrm{K}_{2} \mathrm{~S}_{2} \mathrm{O}_{8}$
$(21.6 \mathrm{~g})$ and isoprene $(80 \mathrm{~mL})$ were then added and stirred for $2 \mathrm{~h}$ at room temperature to complete the monomer adsolubilization step. The reaction mixture was then heated to $70^{\circ} \mathrm{C}$ and polymerization was carried out for $1 \mathrm{~h}$. Finally, the modified silica was washed with water to remove the CTAB from the outer layer of the polyisoprene film and dried at $75^{\circ} \mathrm{C}$ for $24 \mathrm{~h}$. Each batch of admicellar polymerization yielded $800 \mathrm{~g}$ of modified silica. In this study, 7 polymerization batches were carried out to obtain an adequate amount of modified silica. The resulting modified silica was combined prior to use.

The modified silica was examined by Fourier-transform infrared (FTIR, Bruker Equinox 55) spectroscopy, thermogravimetric analysis (TGA, Perkin Elmer STA 6000) and scanning electron microscopy (SEM, FEI Quanta 400).

Compound preparation: Table- 1 lists the compounds used in this study and Table- 2 summarizes the optimized mixing conditions for each compound type. The optimal formulation and mixing conditions used in this study are based on a preliminary study, in which the DPG contents, initial mixer temperature settings and filler-rubber mixing intervals were varied $^{21}$. Mixing was performed using an internal mixer with a $500 \mathrm{~cm}^{3}$ mixing chamber (Chareon Tut., Thailand) at a fill factor of 0.7 and a rotor speed of $60 \mathrm{rpm}$. The initial temperature settings of the mixer and the filler-rubber mixing interval were adjusted according to the conditions listed in Table-2.

\begin{tabular}{|c|c|c|c|c|c|}
\hline \multicolumn{6}{|c|}{$\begin{array}{c}\text { TABLE-1 } \\
\text { COMPOUND FORMULATION }\end{array}$} \\
\hline \multirow{2}{*}{ Ingredients } & \multicolumn{5}{|c|}{ Quantity (phr) } \\
\hline & $\mathrm{A}$ & B & $\mathrm{C}$ & $\mathrm{D}$ & $\mathrm{E}$ \\
\hline Rubber (STR 20) & 100.0 & 100.0 & 100.0 & 100.0 & 100.0 \\
\hline Carbon black (N330) & 60.0 & - & - & 30.0 & 30.0 \\
\hline Unmodified silica & - & 60.0 & - & 30.0 & - \\
\hline Modified silica & - & - & 60.0 & - & 30.0 \\
\hline Silane (TESPT) & - & 4.8 & - & 2.4 & - \\
\hline DEG & - & 3.6 & 3.6 & 1.8 & 1.8 \\
\hline DPG & 0.1 & 0.9 & 0.1 & 0.45 & 0.1 \\
\hline \multicolumn{6}{|c|}{$\begin{array}{l}\text { All compounds contain TDAE oil 8.0; } \mathrm{ZnO} 4.0 \text {; Stearic acid 1.5; 6PPD } \\
\text { 1.5; TMQ 2.0; wax 0.5; TBBS } 1.0 \text {; sulfur } 1.9 \mathrm{phr}\end{array}$} \\
\hline \multicolumn{6}{|c|}{$\begin{array}{c}\text { TABLE-2 } \\
\text { MIXING CONDITIONS }\end{array}$} \\
\hline Parameters & & $\mathrm{A}$ & B & $\mathrm{C}$ & $E$ \\
\hline Initial mixer temper & setting & 90 & 90 & $100 \quad 90$ & 100 \\
\hline Rubber-filler mixing i & $\mathrm{val}(\mathrm{mi}$ & 8 & 10 & 10 & 8 \\
\hline
\end{tabular}

Natural rubber was initially masticated for $2 \mathrm{~min}$. For formulations A to C, half of the filler (together with silane, DEG and DPG, if any) was added and mixed for half of the duration of the rubber-filler mixing interval (i.e. 4 or $5 \mathrm{~min}$ ) prior to adding the second half of the filler (and silane, DEG, DPG, if any) together with TDAE oil. Mixing was then continued to the full intervals, i.e. 8 and 10 min. For formulations D and $\mathrm{E}$ (mixed filler), silica plus silane, DEG and DPG were mixed for the first half of the duration of the rubber-filler mixing interval, which was followed by the incorporation of carbon black and mixing to the full intervals. After completing the rubber-filler mixing interval, the other ingredients $(\mathrm{ZnO}$, stearic acid, 2,2,4-trimethyl-1,2-quinoline, 6PPD and wax) were added and mixed for 3 min before discharging the compounds. 
After cooling and storing overnight, TBBS and sulfur were added to produce the final compounds.

Determination of the properties of the unvulcanized compounds and rubber vulcanizates: The Mooney viscosities of the compounds were tested using a Mooney viscometer at $100{ }^{\circ} \mathrm{C}$ with large rotor according to ASTM D1646. The cure characteristics were determined using a Moving Die Rheometer at $150{ }^{\circ} \mathrm{C}$ according to ASTM D5289.

The vulcanizates were prepared by press-curing to the optimum vulcanization time $\left(\mathrm{t}_{90}\right)$ at $150{ }^{\circ} \mathrm{C}$. The tensile properties were determined using dumbbell-shaped specimens (die type C) at a crosshead speed of $500 \mathrm{~mm} / \mathrm{min}$ according to ASTM D412 using a Hounsfield tensile tester. The tear strength was tested using an angle shaped specimen (die type C) according to ASTM D624. The hardness (Shore A) and Akron abrasion index were determined according to ASTM D2240 and BS903: Part A9, respectively.

The dynamic mechanical properties of the vulcanizates were analyzed using a dynamic mechanical thermal analyzer (DMTA V, Rheometric Scientific) under tension mode at a frequency of $10 \mathrm{~Hz}$, heating rate of $5{ }^{\circ} \mathrm{C} / \mathrm{min}$ and strain of $0.05 \%$. The filler dispersion in the rubber compounds was characterized by SEM. The cryogenic-cracked surface was coated with gold prior to analysis.

\section{RESULTS AND DISCUSSION}

Characterization of the modified silica: The FTIR spectra of both unmodified and modified silica, as shown in Fig. 1, showed the O-H stretching bands at $3427 \mathrm{~cm}^{-1}$ and Si-O vibration at 1099 and $790 \mathrm{~cm}^{-1}$. The modified silica clearly showed the characteristic peaks assigned to the functional groups of the polyisoprene film, i.e. the absorption bands at 2920 and $2851 \mathrm{~cm}^{-1}$ for the $\mathrm{C}-\mathrm{H}$ stretching vibration, 1628 $\mathrm{cm}^{-1}$ for the $\mathrm{C}=\mathrm{C}$ stretching vibration and $1457 \mathrm{~cm}^{-1}$ for the $\mathrm{C}-\mathrm{H}$ bending vibration. This confirms the presence of a polyisoprene film on the silica surface after chemical modification.

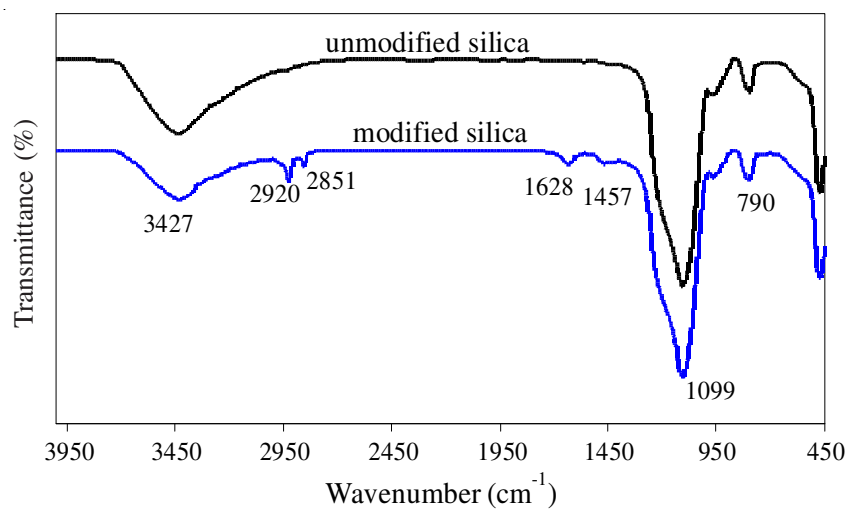

Fig. 1. FTIR spectra of the unmodified and modified silica

The TGA thermogram (Fig. 2) of the unmodified silica showed a decrease in weight at the early stages of heating due to moisture adsorbed on the silica surface. At $800^{\circ} \mathrm{C}$, the weight of unmodified silica remained at $92.5 \%$. This is different from the thermogram of modified silica, where three weight loss steps were observed. The first and second weight loss was attributed to moisture and the decomposition of cetyltrimethylammonium bromide (CTAB), respectively. Polyisoprene began to decompose at approximately $300{ }^{\circ} \mathrm{C}$ with the maximum rate of weight loss at $349.8^{\circ} \mathrm{C}$. At the end of the test, the weight of modified silica remained at $77.7 \%$.

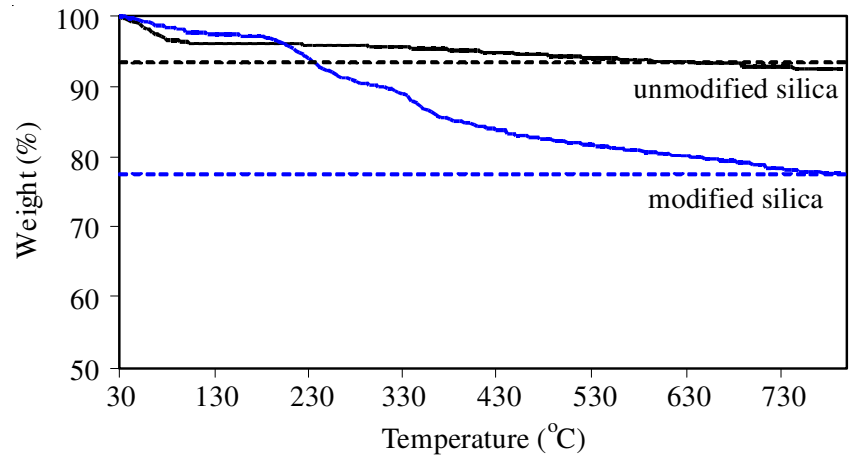

Fig. 2. TGA thermograms of the unmodified and modified silica

Fig. 3 shows SEM images of both types of silica. The unmodified silica showed a smaller agglomerate size compared to the modified one, which has a polyisoprene film on the surface. The increase in the agglomerate size of modified silica with a polymer film coated on the surface is in agreement with Thammathadanukul et al. ${ }^{22}$, who examined the admicellar polymerization of styrene and butadiene monomers on the silica surface.

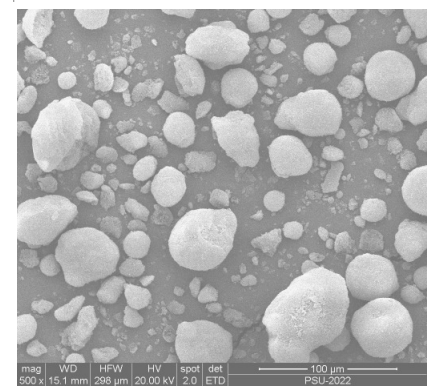

(a) unmodified silica

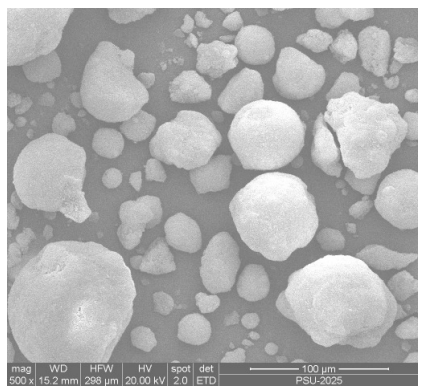

(b) modified silica
Fig. 3. SEM images of unmodified and modified silica (X500)

Processing properties: The mixing of fillers into rubber compounds increase the mixing torques. As shown in Fig. 4, the compound filled with unmodified silica with silane showed the highest torque, whereas the modified silica showed the lowest. The polyisoprene film on the silica surface enhanced the compatibility between the modified silica and natural rubber and improved the dispersability. Despite the presence of silane coupling agent, the unmodified silica showed strong hydrogen bonding between the agglomerates and required a higher shear force to break up the agglomerates into aggregates. Regarding carbon black, the filler agglomerates are held mainly by weak vander Waals forces and can be dispersed easily in non-polar rubber. The lower mixing torques indicated lower mixing energy, so the modified silica clearly has an advantage in term of processing.

Fig. 5 presents the Mooney viscosities of the natural rubber compounds filled with various types of fillers. The compound filled with modified silica showed the lowest Mooney 
viscosity, which is in accordance with the mixing torque shown in Fig. 4. The presence of polyisoprene chains on the silica surface facilitates the movement of rubber molecules around the filler aggregates and provides less restriction to deformation.

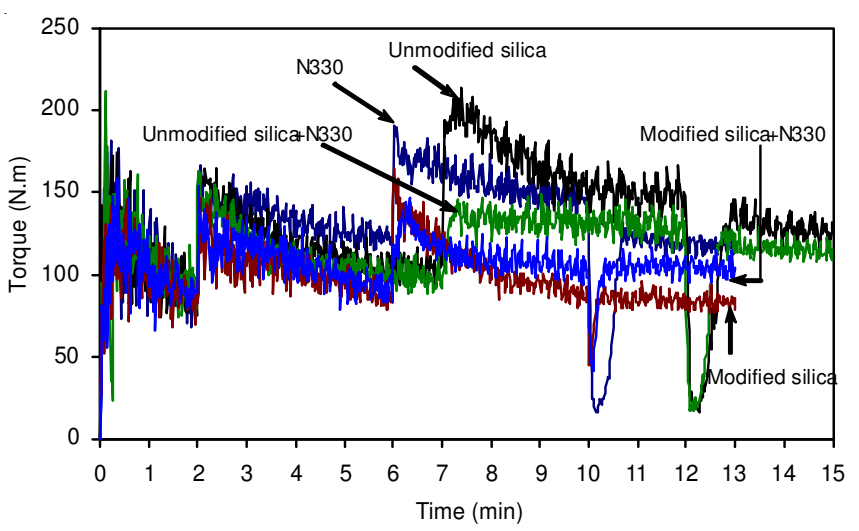

Fig. 4. Mixing torques of the natural rubber compounds filled with various types of fillers

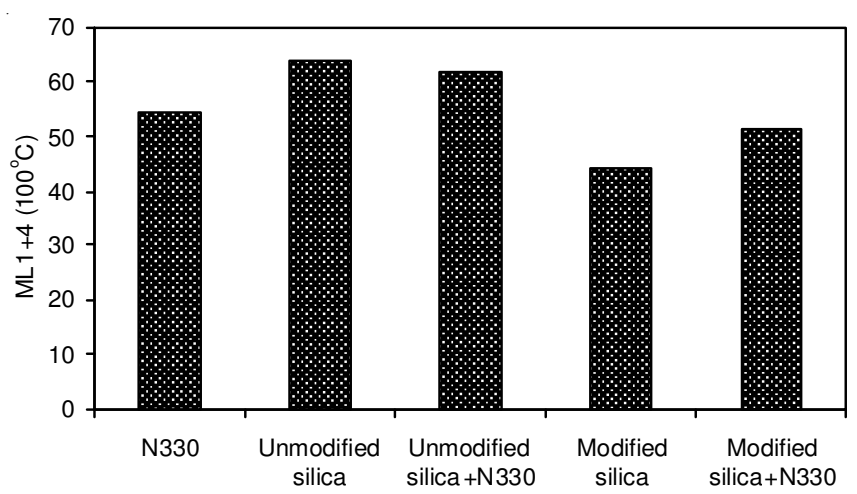

Fig. 5. Mooney viscosities of the natural rubber compounds filled with various types of fillers

The compounds filled with different types of fillers showed similar cure times but a remarkable difference in the maximum torque (Fig. 6). The use of silane in combination with unmodified silica results in strong chemical interactions between the silica and rubber. The ethoxy groups of silane react with the silanol groups of silica and at high temperatures, the tetrasulfane chain of TESPT silica can dissociate and react with the rubber chain to form a linkage between silica and rubber $^{23}$. In addition, free sulfur can be generated from the dissociation of TESPT, which can result in the formation of crosslinks between the rubber molecules. This premature crosslinking has been reported ${ }^{11,24,25}$. These chemical linkages in the silica-TESPT system cause higher maximum torque and torque increase $\left(\mathrm{M}_{\mathrm{H}}-\mathrm{M}_{\mathrm{L}}\right)$ compared to the compounds with carbon black and modified silica, respectively.

Physical and mechanical properties: Different types of fillers affect the stress-strain properties of natural rubber compounds, as shown in Figs. 7 and 8. When the elongation is higher than $100 \%$, the N330-filled compound exhibited a higher modulus than the unmodified silica-filled compound and modified silica-filled counterpart. Carbon black consists mainly of carbon atoms and is compatible with hydrocarbon rubber. Fukahori ${ }^{26}$ suggested that a large increase in stress with increasing strain amplitude in the carbon black-reinforced rubbers is due to the strong stress concentration generated around the carbon particles and its transmission to the entire system. Furthermore, rubber chain adsorption at the crystal boundaries of carbon-black particles forms physical (adsorption) junctions that restrict the chain mobility in the rubbery matrix outside the interface ${ }^{27}$. Despite the formation of chemical bonds between the silica and rubber molecules, the silica-silane system exhibits a lower modulus than the carbon back counterpart, indicating the less restriction of rubber chains outside the filler-rubber interface. The lowest modulus was observed in the modified silica-filled compound, as a result of the CTAB layer and polyisoprene chain at the interface, which facilitate chain mobility. Fig. 9 suggests different interactions at the filler-rubber interface in the carbon black-, silica+silane and modified silica-filled natural rubber compounds. The carbon black-filled natural rubber exhibited a dominant modulus compared to the other types of fillers, as shown in Fig. 7, as well as a higher reinforcing index (M300/M100), as shown in Fig. 10.

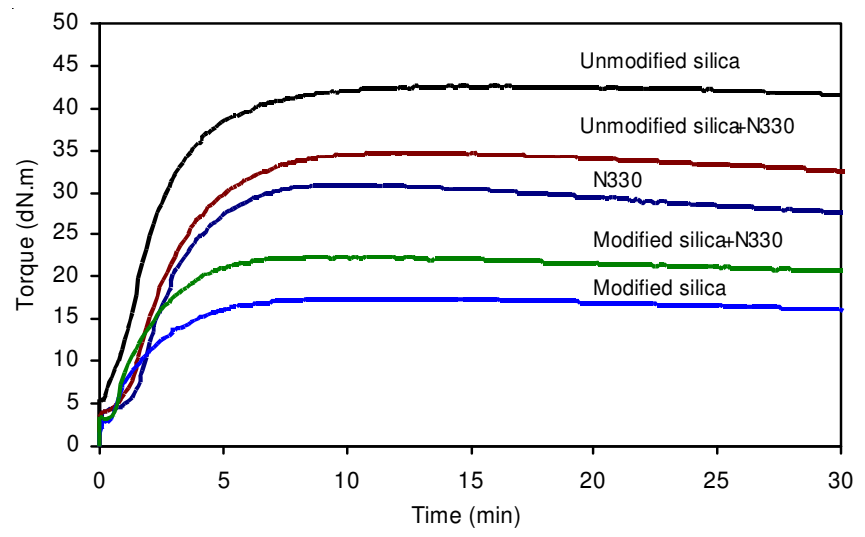

Fig. 6. Cure characteristics of the natural rubber compounds filled with various types of filler

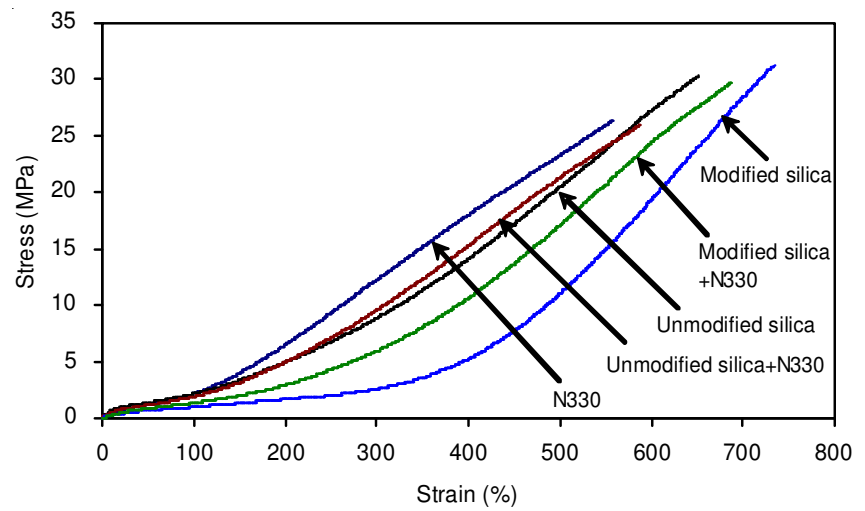

Fig. 7. Stress-strain curves of the natural rubber vulcanizates filled with various types of filler

The higher chain mobility around the filler-rubber interface of the modified silica filled-natural rubber compound, which lowers the modulus, also affects the ultimate properties. Fig. 8 shows that modified silica imparts higher tensile strength and elongation at break compared to the unmodified silica and carbon black, respectively, whereas the mixed filler of silica and carbon black displays intermediate results. The chain 
mobility facilitates the rearrangement of rubber chains upon stretching, as well as strain-induced crystallization in natural rubber.

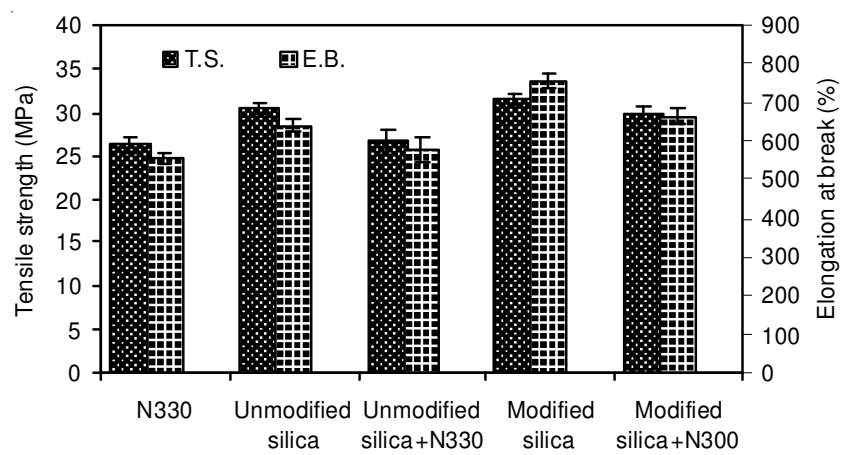

Fig. 8. Tensile strength and elongation at break of the NR vulcanizates filled with various types of filler
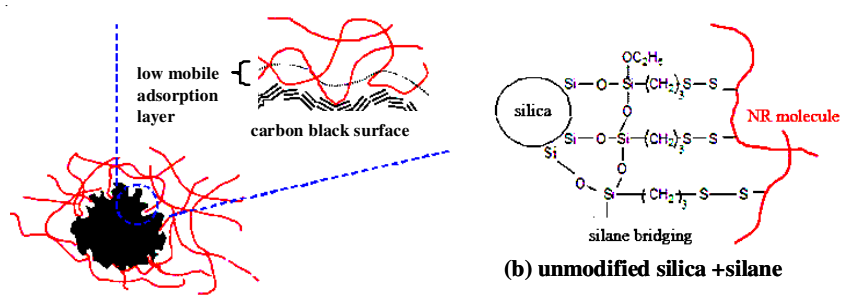

(a) $\mathbf{N 3 3 0}$

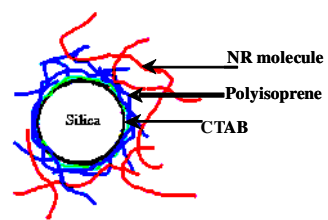

(c) modified silica

Fig. 9. Interactions at the interphase between the filler and rubber
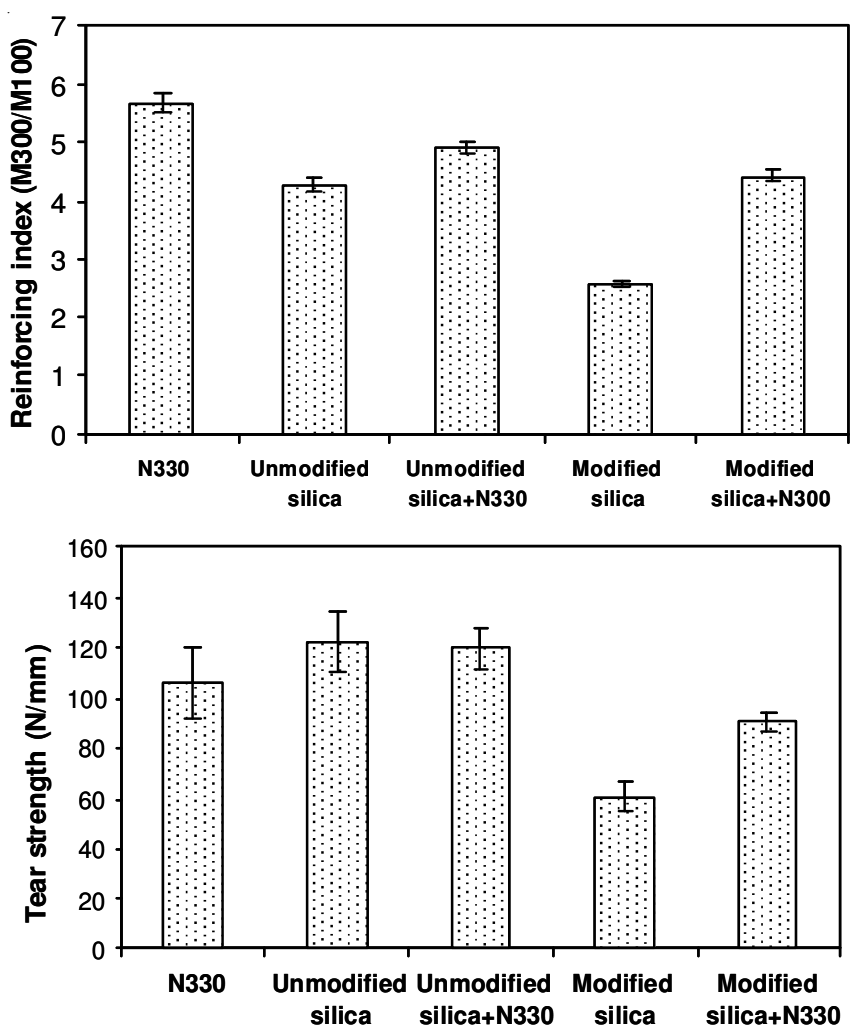

The presence of only physical interactions between silica and rubber in the modified silica-filled natural rubber compound and the indirect adsorption of rubber chains on the silica surface due to the CTAB interlayer has an adverse effect on the reinforcing index, hardness, tear strength and abrasion resistance (Fig. 10). The compound reinforced with carbon black showed a superior reinforcing index and abrasion resistance, whereas the unmodified silica with silane showed higher hardness and tear strength. These properties of the compounds filled with carbon black and silica plus silane are remarkably higher than the compound filled with modified silica.

The superior abrasion resistance of carbon black-filled natural rubber was attributed to physical chain adsorption on the carbon black surface resulting in the formation of polymer layers (hard inner layer and soft outer layer) around the filler particles $^{26}$, which are difficult to abrade using an Akron abrasive wheel. On the other hand, silica-silane filled natural rubber consists of chemical bonds between the filler and rubber, i.e. rigid filler-rubber interaction and displays inferior abrasion resistance. In the case of the unmodified silica-silane system, the poor compatibility between silica and rubber at some spots not covered with silane also had an adverse effect on abrasion. The obviously low abrasion resistance of the modified silica-filled natural rubber is most likely caused by the CTAB layer, which prevents the direct physical adsorption of rubber chains on the silica surface. Fig. 11 shows the abraded surface of the natural rubber vulcanizates filled with carbon black, unmodified silica and modified silica.

When rubber is abraded without a change in direction, sets of parallel ridges are often found on the surface of the samples at right angles to the direction of motion, which are called "abrasion patterns" 28 . The decrease in rubber stiffness
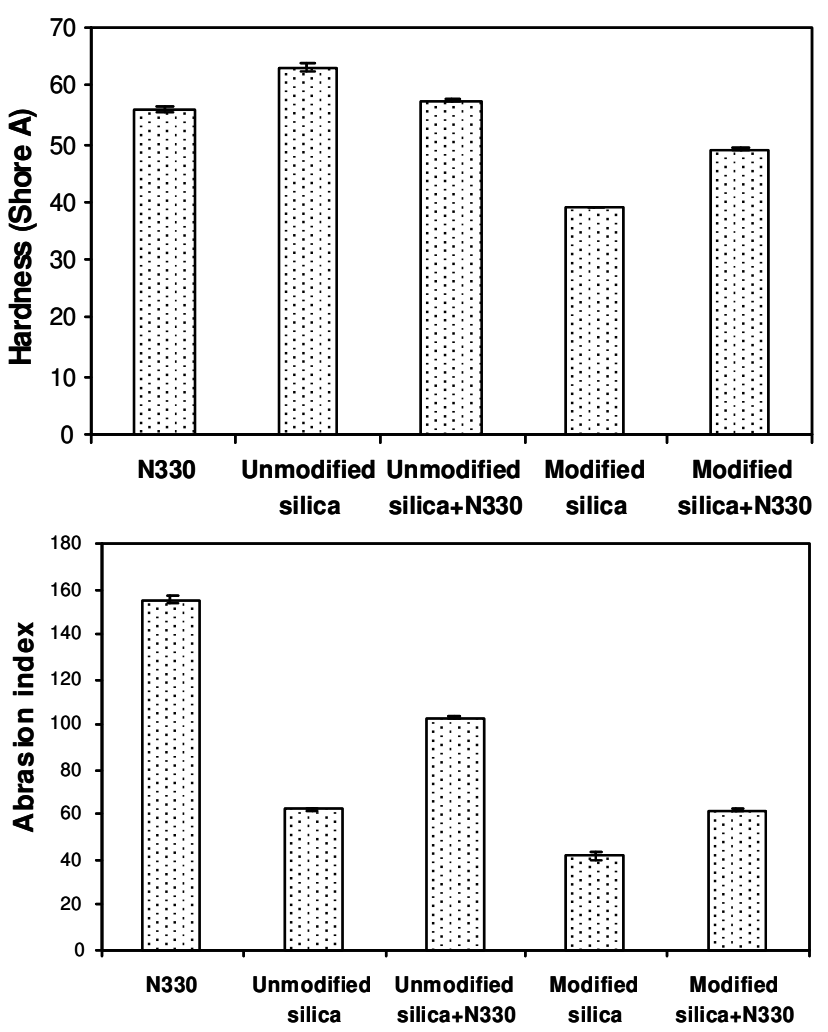

Fig. 10. Reinforcing index, hardness, tear strength and Akron abrasion index of the natural rubber vulcanizates filled with various types of filler 


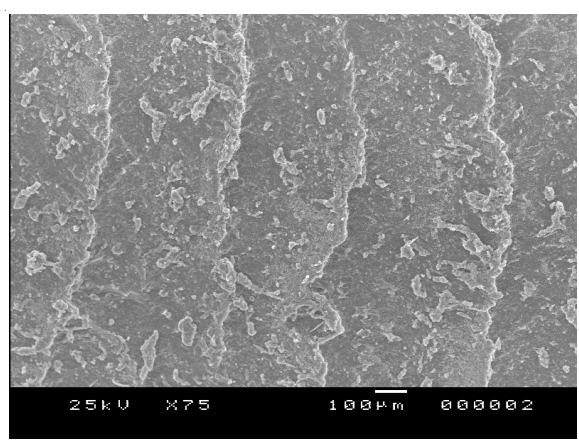

(a) N330

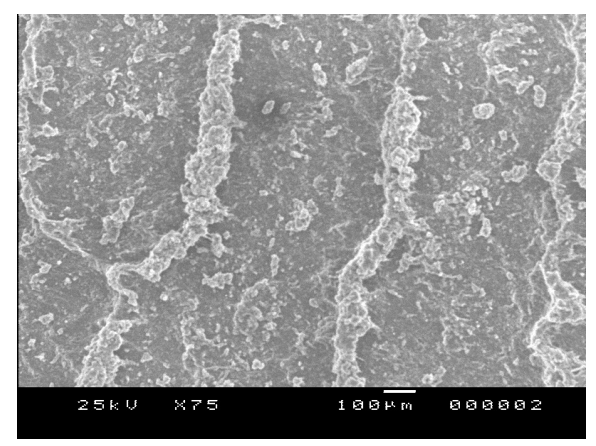

(b) unmodified silica + silane

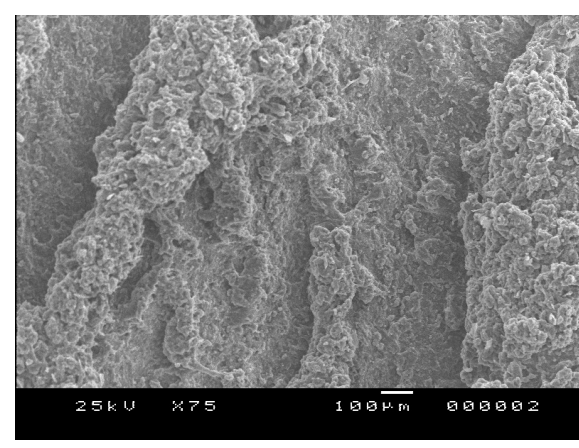

(c) modified silica

Fig. 11. Abrasion pattern showing parallel ridges of the NR vulcanizates after the Akron test (SEM at X75)

increases the abrasion pattern intensity and the rate of abrasion. The modified silica filled natural rubber vulcanizate, which has the lowest modulus, i.e. lowest stiffness and Akron abrasion index, showed large parallel ridges and the most intense abrasion pattern.

Dynamic mechanical properties: The natural rubber vulcanizates containing different types of fillers show similar storage moduli in their glassy state. On the other hand, in their rubbery state, the modified silica filled vulcanizate had the lowest storage modulus. This was attributed to the polyisoprene and CTAB layers adhered to the silica surface, which facilitate chain mobility, in accordance with the static modulus observed in the tensile test (Fig. 12).

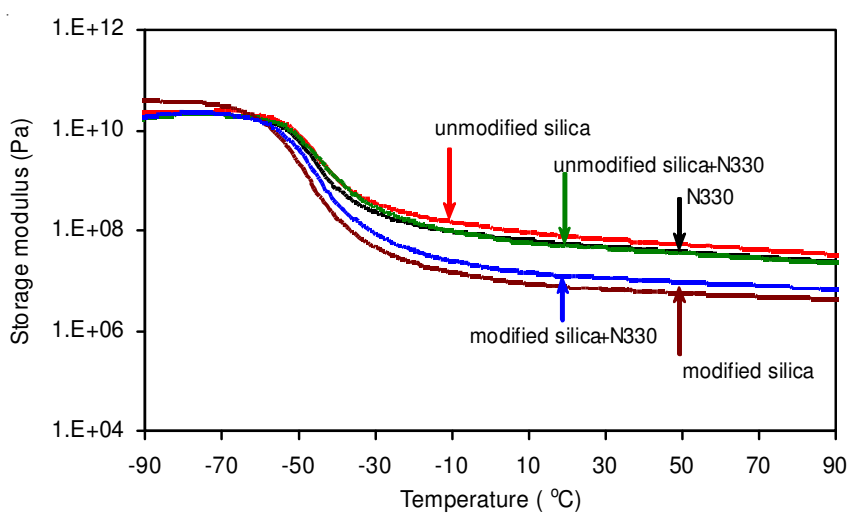

Fig. 12. Storage modulus of the natural rubber vulcanizates filled with various types of filler

The modified silica-filled natural rubber vulcanizate exhibited a higher loss tangent at $0^{\circ} \mathrm{C}$ and a lower loss tangent at $60{ }^{\circ} \mathrm{C}$ compared to those of silica-silane- and carbon blackfilled compounds. This suggests that the modified silica has advantages in term of the wet grip and rolling resistance compared to other types of fillers. On the other hand, the inferior modulus, hardness, tear strength and abrasion resistance obviously limit the application of this modified silica for tyre compounds (Fig. 13).

SEM of the cryogenic-fractured surface of natural rubber vulcanizates filled with three different types of fillers (Fig. 14) showed that all filler types studied exhibited fine dispersion in the natural rubber matrix. The natural rubber containing the unmodified silica exhibited a few agglomerates despite having a silane coupling agent but the silica was distributed almost uniformly in the rubber. For the modified silica, the

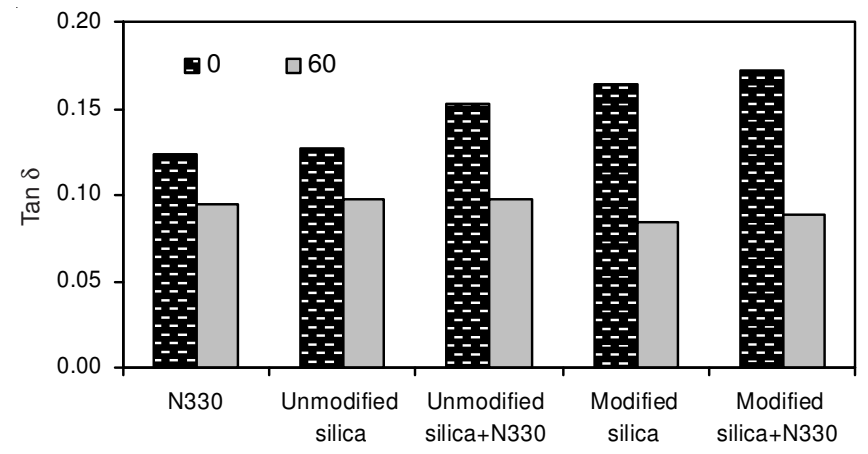

Fig. 13. Loss tangent at 0 and $60^{\circ} \mathrm{C}$ of the natural rubber vulcanizates filled with various types of filler

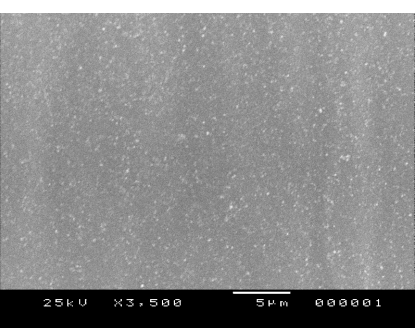

(a) N330

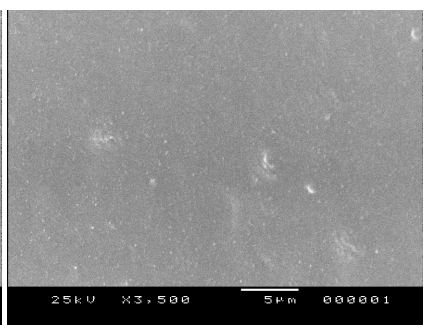

(b) unmodified silica + silane

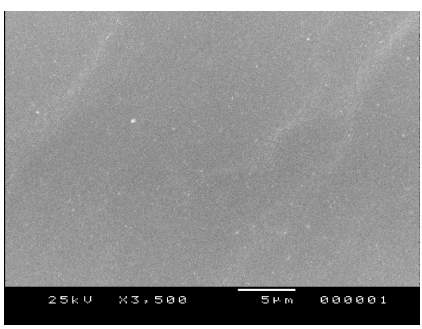

(c) modified silica

Fig. 14. SEM images of NR vulcanizates filled with N330, unmodified silica and modified silica (X3500)

coated polyisoprene film on the silica surface enhanced the compatibility with natural rubber molecules and could be dispersed easily in the rubber matrix.

\section{Conclusion}

Admicellar polymerization-surface modified silica was used to improve the compatibility between silica and hydrocarbon rubber. The characterization data of the modified silica confirmed the presence of a polyisoprene film on the silica surface. The modified silica can be dispersed easily in the natural rubber compound resulting in low Mooney viscosity. 
The filled-natural rubber compounds exhibit different mechanical and dynamic properties due to the different types of interactions between the filler and rubber. The modified silica provided superior tensile strength, elongation at break and loss tangent at 0 and $60^{\circ} \mathrm{C}$, but inferior modulus, hardness, tear and abrasion resistances, compared to the conventional carbon black and unmodified silica with silane coupling agent. The modified silica is evidently unsuitable for tyre tread compounds but may have other applications with less technical requirements due to its processing advantages.

\section{ACKNOWLEDGEMENTS}

This study was supported by the Thailand Research Fund (TRF) (contract grant number RDG5350016).

\section{REFERENCES}

1. R. Rauline, EP Patent 0501227 (1992)

2. H.-D. Luginsland and W. Niedermeier, Rubber World, 228, 34 (2003).

3. S. Wolff, Rubber Chem. Technol., 69, 325 (1996).

4. A.I. Medalia, Rubber Chem. Technol., 47, 411 (1974).

5. J.T. Byers, Rubber Chem. Technol., 75, 527 (2002)

6. M.P. Wagner, Rubber Chem. Technol., 49, 703 (1976).

7. H.-D. Luginsland, J. Fröhlich and A. Wehmeier, Rubber Chem. Technol., 75, 563 (2002)

8. J.W. ten Brinke, P.J. van Swaaij, L.A.E.M. Reuvekamp and J.W.M. Noordermeer, Rubber Chem. Technol., 76, 12 (2003).

9. L.A.E.M. Reuvekamp, J.W. ten Brinke, P.J. van Swaaij and J.W.M. Noordermeer, Kautsch. Gummi Kunstst., 55, 41 (2002).
10. W.K. Dierkes, J.W.M. Noordermeer, K. Kelting and A. Limper, Rubber World, 229, 6 (2004).

11. W. Kaewsakul, K. Sahakaro, W. Dierkes and J.W.M. Noordermeer, Rubber Chem. Technol., 85, 277 (2012).

12. S.-S. Choi, J. Appl. Polym. Sci., 83, 2609 (2002).

13. S.-S. Choi, J. Appl. Polym. Sci., 79, 1127 (2001).

14. H. Yan, K. Sun, Yo. Zhang and Yi. Zhang, Polym. Test., 24, 32 (2005).

15. F. Cataldo, Macromol. Mater. Eng., 287, 348 (2002).

16. K. Sahakaro and S. Beraheng, J. Appl. Polym. Sci., 109, 3839 (2008).

17. M. Marquez, B.P. Grady and I. Robb, Colloid Surf. A, 266, 18 (2005).

18. P. Nontasorn, S. Chavadej, P. Rangsunvigit, J.H. O'Haver, S. Chaisirimahamorakot and N. Na-Ranong, Chem. Eng. J., 108, 213 (2005).

19. P. Rangsunvigit, P. Imsawatgul, N. Na-Ranong, J.H. O'Haver and S. Chavadej, Chem. Eng. J., 136, 288 (2008).

20. C. Poochai, P. Pae-on and T. Pongprayoon, In Proceedings of World Academy of Science, Engineering and Technology (WASET), Tokyo, Japan, pp.969-973 (2010).

21. P. Toh-ae, M. Sc. Thesis, Department of Rubber Technology and Polymer Science, Prince of Songkla University, Pattani, Thailand (2011).

22. V. Thammathadanukul, J.H. O'Haver, J.H. Harwell, S. Osuwan, N. NaRanong and W.H. Waddell, J. Appl. Polym. Sci., 59, 1741 (1996).

23. U. Görl, A. Hunsche, A. Müller and H.G. Koban, Rubber Chem. Technol., 70, 608 (1997).

24. S. Wolff, Rubber Chem. Technol., 55, 967 (1982).

25. S.-S. Choi, I.-S. Kim and C.-S. Woo, J. Appl. Polym. Sci., 106, 2753 (2007).

26. Y. Fukahori, J. Appl. Polym. Sci., 95, 60 (2005).

27. V.M. Litvinov, R.A. Orza, M. Klüppel, M. van Duin and P.C.M.M. Magusin, Macromolecules, 44, 4887 (2011).

28. A. Schallamach, Wear, 1, 384 (1957). 